\title{
$9 \mathrm{~km}$ in den Suizid
}

\section{Tod an der langen Leine}

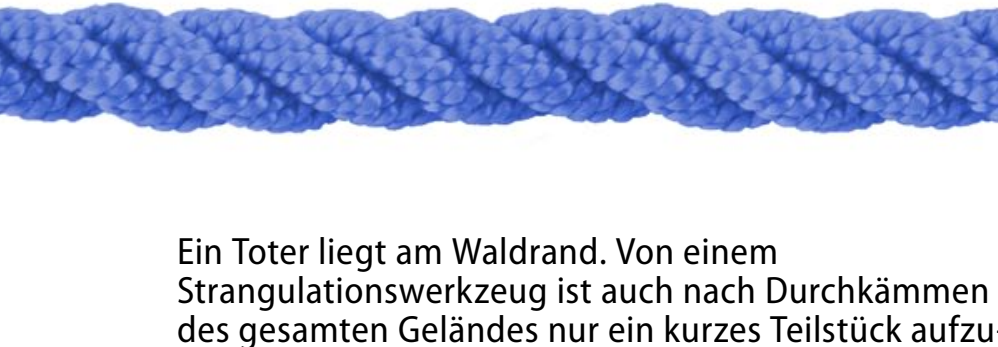 finden. Ein Gewaltverbrechen?}

Die Leiche des 63-jährigen Mannes liegt in der Wiese, am Hals eine fast horizontal verlaufende, tiefe Strangfurche. Direkt daneben steht sein Kombi; Fahrertür und Heckklappe offen. Im Kofferraum findet die Spurensicherung ein kurzes, abgerissenes Stück eines blauen Kunststoffseils, passend zur Strangfurche und mit Epidermisspuren des Toten. Auf der Oberkante der Fahrersitzrückenlehne finden sich Faserspuren des Seils.

Dr. Stefano Longato, Institut für Gerichtliche Medizin, Medizinische Universität Innsbruck, berichtet, bei der Obduktion habe man starke Einblutungen in die Halsweichteile gefunden, sowie einen kompletten Abriss der Trachea kaudal des Larynx, eine Ruptur der Bandscheibe zwischen HWK 4 und 5, eine Intimaruptur der linken und eine Dissektion der rechten Arteria carotis communis proximal der Bifurkation. In den Bronchien fand sich aspiriertes Blut.

\section{"Innere Schienung" der Halsweichteile}

Im Rahmen der weiteren Ermittlungen entdeckt die Kriminalpolizei in dem etwa neun Kilometer von der Leichenfundstelle entfernten Dorf Ettenheim auf dem Pferdehof des Mannes den Rest des Seils - an einen der äußerst robusten Zaunpflöcke der Koppel geknotet.

Schließlich rekonstruiert man, dass der Mann, der seinen Suizid bereits mehrfach angekündigt hatte, das Seil zunächst an dem Pflock festband, durch die offene Heckklappe seines Kombis von hinten zum Fahrersitz führte und es sich dort um den Hals schlang. Er fuhr los, das Seil spannte sich und riss. „Durch die massive Einblutung in die Halsweichteile kam es zu einer vorübergehenden Schienung und Stabilisierung der verletzten Halsstrukturen“, erklärt Longato.

\section{Überleben trotz massiver Strangullation}

In diesem Zustand fuhr der Mann dann seinem Tod entgegen - neun Kilometer weit über die Landstraße und durch den Wald bis kurz vor Fritzing, wo er sein Auto am Waldrand parkte, aus dem Auto ausstieg und tot ins Gras fiel. „Durch das Bewegen des Kopfes wurde die innere Schienung der Halsweichteile wieder aufgehoben und der Mann erstickte", so Longatos Erklärung.

Angesichts der Strecke, die der Suizidant zurücklegte, muss er noch mindes- tens 15 Minuten lang bei Bewusstsein geblieben sein.

Für jemand mit solch massiven inneren Verletzungen des Halses ist das sehr ungewöhnlich, wenn auch nicht vollkommen ausgeschlossen. So konnte im Juni 2001 in Edinburgh eine 21-jährige Frau noch gerettet werden, nachdem sie sich massive Strangulationsverletzungen durch einen in die Speichen einer Fahrradrikscha geratenen Schal zugezogen hatte [1].

Weniger Glück im Unglück hatte die US-amerikanische Tänzerin Isadora Duncan (1877-1927). Sie starb noch am Unfallort, nachdem sich ihr Schal in den Speichen ihres anfahrenden Sportwagens verfing.

(Thomas Bißwanger-Heim)
Gowens PA et al, Emerg Med J 2003, 20:391-3 Longato S, Überraschend lange Handlungsfähigkeit nach massiver Strangulation, 91. Jahrestagung der Deutschen Gesellschaft für Rechtsmedizin 2012, Freiburg

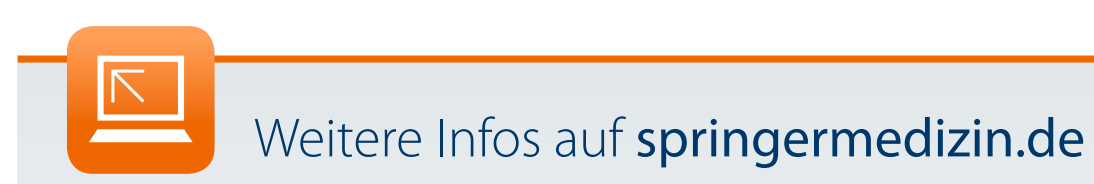

Dossier Rechtsmedizin

Mehr ungewöhnliche Fälle der Rechtsmedizin finden Sie in unserem Dossier Rechtsmedizin $>$ (303650).

Krimi war gestern - Gehen Sie mit dem Rechtsmediziner auf Spurensuche! Informationen zu rechtsmedizinischen Verfahren und Techniken, sowie spannende Fälle von den Kollegen der Rechtsmedizin zum Nachlesen finden Sie online, und zwar unter

- www.springermedizin.de/rechtsmedizin/303650

- Zum spannenden Dossier Rechtsmedizin gelangen Sie über die oben angegebene Web-Adresse, oder indem Sie die (in Klammern gesetzte) ID-Nummer des Dossiers in das Suchfenster auf der Springer Medizin Homepage eingeben. 